\title{
Disease-Specific Expression of Host Genes During Downy Mildew Infection of Arabidopsis
}

\author{
Robin P. Huibers, Mark de Jong, René W. Dekter, and Guido Van den Ackerveken \\ Plant-Microbe Interactions, Department of Biology, Utrecht University, Padualaan 8, 3584 CH Utrecht, The Netherlands
}

Submitted 2 March 2009. Accepted 6 May 2009.

\begin{abstract}
Here, we report on the identification of Arabidopsis genes that are induced during compatible but not during incompatible interactions with the downy mildew pathogen $\mathrm{Hya}$ loperonospora arabidopsidis. This set of so-called compatible specific (CS) genes contrasts with the large group of defense-associated genes that is differentially expressed during both compatible and incompatible interactions. From the 17 identified CS genes, 6 belong to the ethylene response factor (ERF) family of transcription factor genes, suggesting that these ERF have a role during compatibility. The majority of CS genes are differentially regulated in response to various forms of abiotic stress. In silico analysis of the CS genes revealed an over-representation of dehydration-responsive element/C-repeat binding factor (DREB1A/ CBF3) binding sites and EveningElement motifs in their promoter regions. The CS-ERF are closely related to the CBF transcription factors and could potentially bind the DREB1A/CBF3 promoter elements in the CS genes. Transcript levels of CS genes peak at 2 to 3 days postinoculation, when pathogen growth is highest, and decline at later stages of infection. The induction of several CS genes was found to be isolate specific. This suggests that the identified CS genes could be the direct or indirect targets of downy mildew effector proteins that promote disease susceptibility.
\end{abstract}

Most plant species are nonhosts for a given pathogen. This is due to the effective activation of a basal defense response that is triggered by the detection of microbe- or pathogen-associated molecular patterns (MAMPs or PAMPs, respectively) by predominantly cell surface localized receptors (Chisholm et al. 2006). PAMPs, such as bacterial flagellin, trigger a signal transduction cascade that results in the transcriptional activation of defense-associated genes, production of antimicrobial compounds, and cell wall reinforcements (Nurnberger et al.

\section{R. P. Huibers and M. de Jong contributed equally to this work.}

Corresponding author: G. Van den Ackerveken; Telephone: (0) 30253 3013; Fax: +31 (0) 30253 2837; E-mail: g.vandenackerveken@uu.nl

Current address of R. P. Huibers: Department of Plant-Microbe Interactions, Max-Planck Institute for Plant Breeding Research, Carl-von-LinnéWeg 10, 50829 Cologne, Germany.

Current address of M. de Jong: MicroArray Department, FNWI, University of Amsterdam, Sciencepark 904, room C2.105, Postbus 94215, $1090 \mathrm{GE}$ Amsterdam, The Netherlands.

Current address of R. W. Dekter: NAK tuinbouw, Research \& Development, Sotaweg 25, 2370 AA Roelofarendsveen, The Netherlands.

* The $\boldsymbol{e}$-Xtra logo stands for "electronic extra" and indicates that three supplemental tables and one supplemental figure are published online.
2004; Zipfel and Felix 2005). However, basal defense responses do not result in resistance in compatible plant-pathogen interactions. Pathogens have to actively suppress MAMP- or PAMPtriggered responses via so-called effector proteins for compatibility.

For bacterial effector proteins, it has been shown that they can interfere with a large variety of cellular defense responses, including cell wall-mediated defense responses, hormone signaling, programmed cell death, and nonhost disease resistance (Grant et al. 2006). For example, the abscisic acid (ABA) signaling pathway was discovered as a major target of effectors secreted by Pseudomonas syringae. Transcript profiling identified a prominent group of effector-induced genes that are associated with the biosynthesis of and responsiveness to ABA. Levels of ABA increase during bacterial colonization and bacterial growth is reduced in an ABA biosynthetic mutant, suggesting that ABA signaling suppresses activated defense responses (de Torres-Zabala et al. 2007; Truman et al. 2006). Alternatively, pathogen effectors can directly interfere with host gene transcription. The nuclear localized AvrBs3 effector protein of Xanthomonas spp. induces more then 20 genes in susceptible pepper plants (Kay et al. 2007; Marois et al. 2002).

For fungal and oomycete pathogens, hardly anything is known about host genes that are specifically activated during the infection process and not during plant defense. In flax, the fis 1 gene was shown to be induced by rust fungi (Ayliffe et al. 2002). However, overexpression and silencing of fis 1 , which is involved in proline catabolism, did not have an effect on the development of rust disease (Mitchell et al. 2006). Gene profiling of a compatible interaction between potato and Phytophthora infestans revealed the specific downregulation of a plastidic carbonic anhydrase gene (Restrepo et al. 2005). Silencing of the gene resulted in more pathogen growth, suggesting that downregulation aids the infection process.

Several reports have shown that changes in host gene-expression induced upon inoculation with virulent or avirulent pathogen isolates or strains are remarkably similar. Differences are predominantly seen in timing and level of gene expression (Li et al. 2006a; Tao et al. 2003). These reports support the view that resistance $(R)$-gene-mediated responses accelerate and amplify MAMP- or PAMP-triggered responses, resulting in the transcriptional activation of predominantly similar defense-associated genes (Jones and Dangl 2006). Little attention, however, has been paid to the specific differences between compatible and incompatible interactions.

Here, we report on the changes in gene expression in Arabidopsis in response to infection with an avirulent and virulent isolate of Hyaloperonospora arabidopsidis. The gene expression changes in both interaction types were found to be very similar. More than $97 \%$ of the genes that become activated or repressed did so in both the compatible and incompatible inter- 
actions. However, 17 genes were found to be compatible specific (CS), including six ethylene response factor (ERF) transcription factor genes. In silico promoter analyses revealed that CS gene promoters are enriched for EveningElements and dehydration-responsive element/C-repeat binding factor (DREB1A/CBF3) binding sites. Several CS genes were highly induced during the initial phase of infection whereas expression levels declined at later stages of infection. The induction of several CS genes was found to be isolate dependant. This suggests that the identified CS genes could be the direct or indirect targets of downy mildew effector proteins that promote disease susceptibility.

\section{RESULTS}

Transcriptome changes in Arabidopsis in response to infection with compatible and incompatible downy mildew isolates.

To identify CS genes, expression profiles were generated from Arabidopsis seedlings (Landsberg erecta [Ler]) inoculated with a compatible (Cala2) and an incompatible (Waco9, recognized by $R P P 5$ ) $H$. arabidopsidis isolate and compared with a common mock treatment. Plant material was harvested at 3 days postinoculation (dpi). At this timepoint, pathogen growth was fully arrested in the incompatible interaction whereas, in the compatible interaction, hyphal growth was extensive and many haustoria were established. The experiment was carried out in triplicate and RNA of each biological replicate was hybridized on four complete Arabidopsis transcriptome microarrays (CATMA). Genes were considered differentially expressed within each biological replicate when they had a $\log _{2}$ ratio of $\leq-0.75$ or $\geq 0.75$ (approximately 1.68 -fold repression or induction, respectively) and a $q$ value $<0.05(P$ value corrected for multiple testing errors using the false discovery rate). For further analysis, only those genes were studied that were differentially expressed in at least two of three biological replicates in either the compatible or incompatible interaction. This resulted in a compatible gene set of 844 genes and an incompatible gene set of 1,052 genes. An overlay was made between both gene sets (Fig. 1), resulting in 185 genes found only in the compatible interaction and 393 genes only in the incompatible interaction. In total, 659 genes were identified as differentially expressed in both interactions. Many of these genes are known to be related to host defense and a selection of genes with their corresponding $\log _{2}$ ratios (average fold change) is listed in Supplementary Table S1.

Transcripts that were identified as differentially expressed in both interactions could be transcriptionally activated in one interaction and transcriptionally repressed in the other. To investigate this, the $\log _{2}$ ratios (based on the average fold change

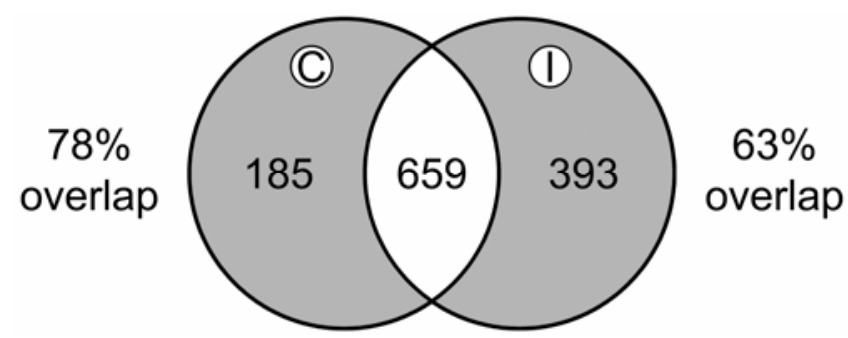

Fig. 1. Overlay of differentially expressed (DE) genes in compatible and incompatible Hyaloperonospora arabidopsidis-Arabidopsis interactions. DE genes were selected based on a $\log _{2}$ ratio of $\leq-0.75$ or $\geq 0.75$ and $q$ values $<0.05$. DE genes were selected based on presence in two of three replicates, resulting in 844 genes for the compatible interaction (C) and 1,052 genes for the incompatible interaction (I). The overlay shows that 659 transcripts are DE in both interactions. over three replicates) of all 659 genes from the overlay between the compatible and incompatible interaction were plotted and the Pearson correlation between the interactions was calculated. The overlapping 659 genes are similarly induced or repressed in both interactions and have an overall correlation $>0.9$ (Fig. 2A).

Genes that are differentially expressed in only one of the interactions could be specific for that interaction. Alternatively, they could have been selected as being differentially expressed
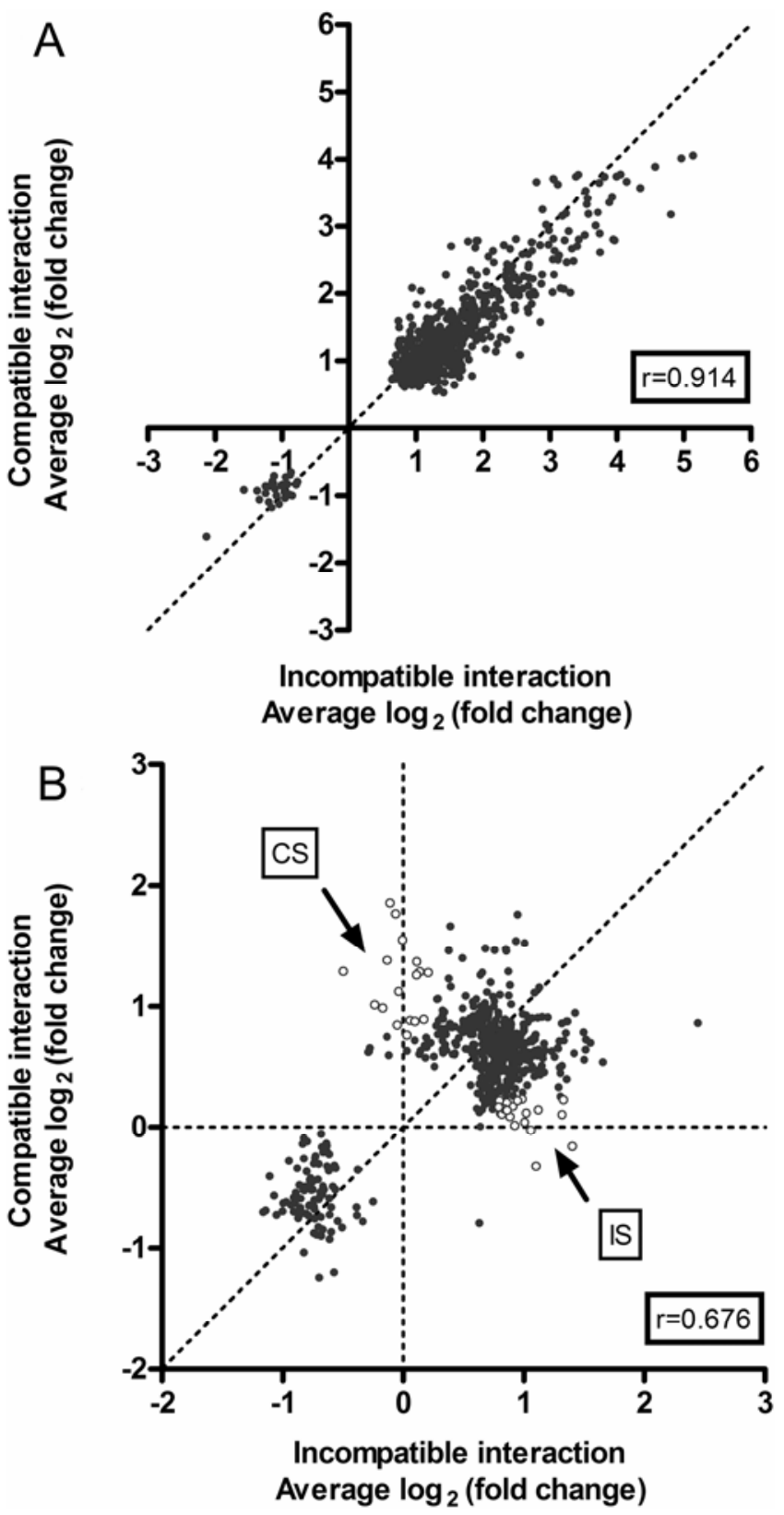

Fig. 2. Correlations between the $\log _{2}$ ratios of differentially expressed (DE) transcripts in a compatible and incompatible interaction. The average $\log _{2}$ fold change of the overlapping and nonoverlapping transcripts was calculated from three biological replicates and plotted. A, Correlation between the 659 overlapping transcripts. B, Correlation between nonoverlapping transcripts (185 and 393). Transcripts in A are strongly correlated and highly DE as opposed to $\mathrm{B}$, where the correlation is lower and $\log _{2}$ ratios are at approximately the selection criteria $(\leq-0.75$ or $\geq 0.75)$. Several genes in B show a specific upregulation for either a compatible (CS) or incompatible interaction (IS) (shown as open dots). These interaction-specific induced genes were selected for a compatible interaction based on $\log _{2}$ ratio $\geq 0.75$ for a compatible interaction and $\log _{2}$ ratio $\leq 0.25$ for an incompatible interaction, or vice versa for an incompatible interaction. 
only in one interaction because their measured expression is just below the lower limit of the selection criteria used $\left(\log _{2}\right.$ ratio of $\leq-0.75$ or $\geq 0.75$ and a $q$ value $<0.05$ ) in the other interaction. To verify this, we calculated the correlation between the $\log _{2}$ ratio (based on the average fold change over three replicates) of the nonoverlapping genes (185 compatible and 393 incompatible) (Fig. 1). A modest correlation between them was found ( $r=0.67$ ) (Fig. 2B). The majority of genes have $\log _{2}$ ratios around the used selection criteria, and induction or repression does not differ much between the compatible and incompatible interaction (Fig. 2B), showing that these genes are also nonspecifically induced or repressed in both interactions.

Interestingly, a small number of genes could be identified as specifically differentially expressed for either interaction. These genes were selected using a Ler-Cala2 $\log _{2}$ ratio $\geq 0.75$ and Ler-Waco9 $\log _{2}$ ratio $\leq 0.25$ for a compatible interaction or vice versa for an incompatible interaction. These selection criteria were based on the rationale that specifically differentially expressed genes should be upregulated in one interaction $\left(\log _{2}\right.$ ratio $\left.\geq 0.75\right)$ and remain relatively unchanged or downregulated in the other interaction $\left(\log _{2} \leq 0.25\right)$ or vice versa. Based on these selection criteria, 36 transcripts showed elevated levels in one interaction only (Fig. 2B, open dots). Of these 36 transcripts, 19 were specific for the compatible (CS genes) interaction and 17 for the incompatible (incompatiblespecific [IS] genes) interaction.

\section{IS and CS gene expression.}

The 36 transcripts that were identified as relatively nonchanging $\left(\log _{2}\right.$ ratio $\left.\leq 0.25\right)$ in either the compatible or incompatible interaction had high $q$ values $(>0.05)$ in the nonchanging condition as expected (high $q$ values reflect a high probability that certain genes are not differentially expressed). However, the used statistical method also assigns high $q$ values to inaccurately measured transcripts. Therefore, these microarray measurements needed verification by quantitative polymerase chain reaction (Q-PCR). CATMA probes (Crowe et al. 2003) for all tested genes were converted to Arabidopsis Genome Initiative (AGI) identifiers (TIGR 6.0; The Institute for Genome Research) for convenience. CATMA probes do not always correspond in a one-to-one relation to AGI identifiers, which can result in a different number of genes with unique AGI codes. Conversion of the 19 CS transcripts based on CATMA probes resulted in 18 AGI codes; 16 of them matched 16 AGI codes, 1 of them matched 2 AGI codes, and 2 had no matches at all. The 16 IS transcripts based on CATMA probes gave 16 AGI codes; 12 of them matched unique AGI codes, 2 of them matched 2 AGI codes each, and 2 had no matches. Nonmatching CATMA probes were discarded and, for the double-matching CATMA probes, unique Q-PCR primers were designed for the genes with an AGI code.

For the Q-PCR analysis, 14 genes that were activated in both interactions were taken along as controls. NPRl, PR-1, and PDF1.2 are not present on the CATMA array but are known to be induced during defense response of the host (Reuber et al. 1998) and, therefore, were included in the analysis. All 14 genes are induced in both interactions (Fig. 3A), confirming the microarray data. In addition, $N P R I, P R-1$, and $P D F 1.2$ show the expected expression pattern for a compatible and incompatible interaction, with NPRl showing similar induction in both interactions and $P R-1$ and $P D F 1.2$ being induced to a higher level in the incompatible interaction. These results show that the microarray data is reliable and confirm that defense-associated expression occurs in both the incompatible and compatible interaction.

IS gene expression was confirmed for only three IS genes by Q-PCR (Fig. 3B, underlined genes). The other IS genes were also induced in the compatible interaction or no induction was observed at all. For the majority of CS genes (14 of 18), upregulation in the compatible but not in the incompatible interaction could be confirmed by Q-PCR (Fig. 3C, underlined genes). Interestingly, more genes could be identified to be specifically induced in the compatible interaction than in the incompatible interaction.

\section{CS transcription factors.}

From the 14 identified CS genes, 3 genes (CS-09, CS-10, and CS-12) belong to the ERF transcription factor family and 1 gene (CS-07) belongs to the basic helix-loop-helix (bHLH) transcription factor family. CS transcription factors are of major interest because they could activate transcription of other genes during compatible interactions. Not all close homologs of the four CS transcription factors were present on the CATMA array. Therefore, we analyzed their expression during compatible and incompatible interactions by Q-PCR.

The ERF family in Arabidopsis comprises 122 genes divided in 10 clades based on domain architecture (Nakano et al. 2006). AtERF\#26 (CS-12) belongs to clade III, whereas AtERF\#111 (CS-10A) and AtERF\#114 (CS-09) belong to clade X (Supplementary Fig. S1). Expression of clade III and X members during compatible and incompatible interactions is shown in Figure 4. In addition to AtERF\#026 (CS-12) in subclade III-b, two homologous ERF genes, AtERF\#024 and AtERF\#025, showed CS expression (designated CS-16 and CS-17) (Fig. 4A). Of the eight ERF in clade X, three showed CS expression; the already identified AtERF\#114 (CS-09) and AtERF\#111 (CS-10) and one additional gene, AtERF\#109 (designated CS-18) (Fig. 4B). Interestingly, AtERF\#108, AtERF\#112, and AtERF\#113 show strong induction in both the compatible and incompatible interaction (Fig. 4B), indicating that members in this clade respond in various ways to downy mildew infection.

bHLH transcription factors are proteins that bind as dimers to specific DNA targets and have been characterized as important regulators in diverse biological processes (Bailey et al. 2003; Li et al. 2006b; Toledo-Ortiz et al. 2003). The closest homologue of bHLH162 (CS-07) according to the Database of Arabidopsis Transcription Factors (Guo et al. 2005) is Atlg10585. This gene was also found to be specifically induced by compatible downy mildew (Fig. 5I). In total, 14 CS genes were identified by microarray analysis and were confirmed by Q-PCR. The addition of three CS genes from the ERF clade III and X and the homologous bHLH factor brings the number of CS genes to 18 .

\section{In silico promoter analysis of CS genes.}

The identified CS genes show enrichment for the class "response to abiotic or biotic stimulus" in the GO category "biological process"; using the TAIR gene ontology functional categorization tool. For several CS genes, it has been described that they respond to abiotic stress conditions (e.g., dehydration, low temperature, and ABA) (Table 1). The publicly available dataset abiostress of the AtGenExpress visualization tool revealed that six CS genes are induced during multiple abiotic stress conditions (Table 2, upper part) (e.g., cold, osmotic stress, salt, drought, wounding, and ABA). Other CS genes are less generally induced by abiotic stress condition (Table 2, lower part).

Genes that are coregulated in a given biological process often share common regulatory elements in their promoters. Because all $17 \mathrm{CS}$ genes are induced during a compatible downy mildew infection and many are responsive to abiotic stress, there could reside similar promoter elements in their respective promoters. To investigate this, the web-based tool Athena (O'Connor et al. 2005) was used to identify and visualize known regulatory elements overrepresented in the promoter 

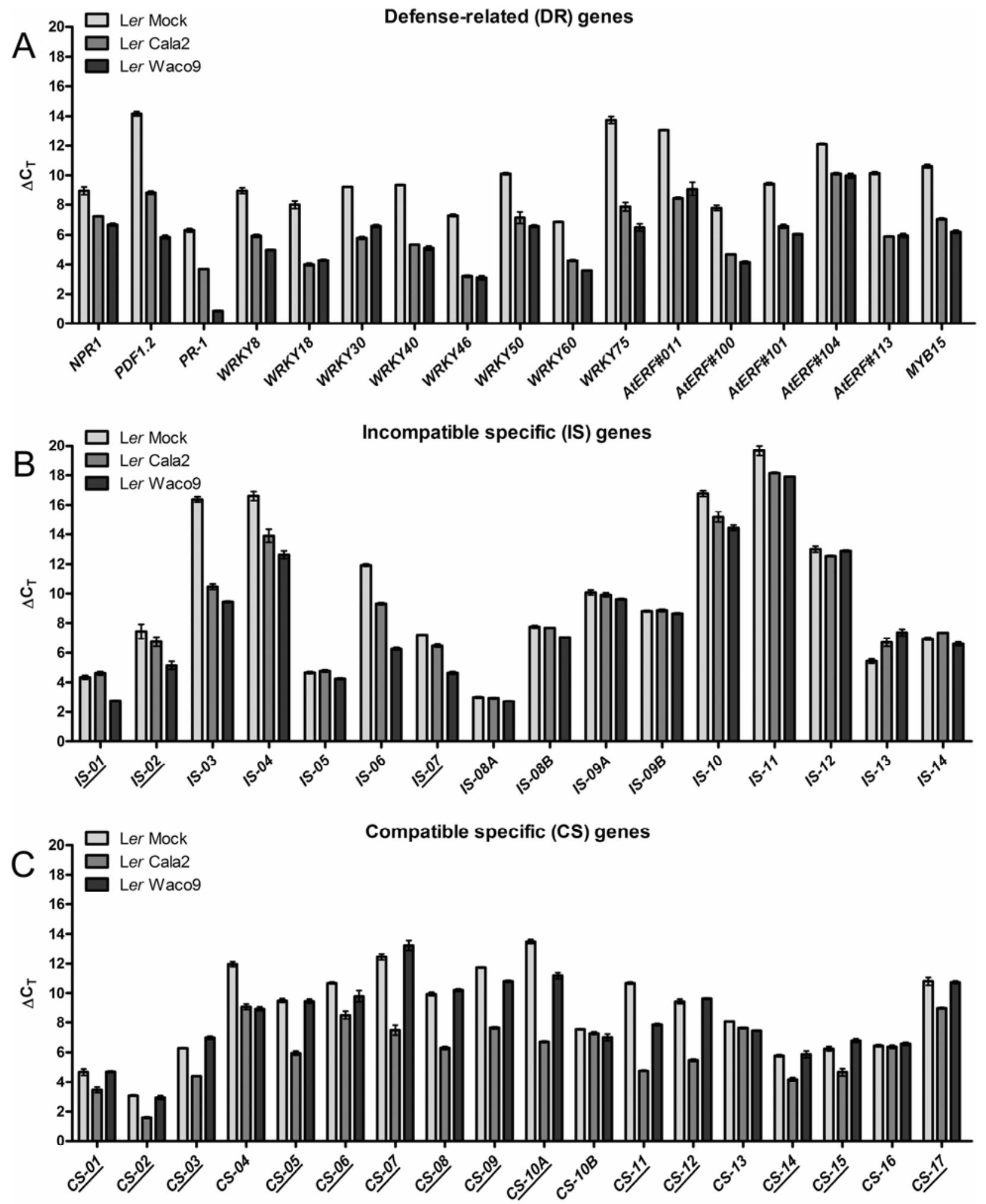

Fig. 3. Relative transcript abundance of defense-related and potential compatible-specific (CS) and incompatible-specific (IS) genes. RNA extracted from each biological replicate for each interaction was pooled (see Material and Methods) and cDNA was synthesized. Note that a lower bar indicates higher transcript abundances in all diagrams and that all measurements were normalized for Arabidopsis Act2-levels (At3g18780). The error-bars are given as standard error of mean. Landsberg erecta (Ler) plants were i) mock-inoculated, ii) inoculated with the compatible isolate Cala2, or iii) inoculated with the incompatible isolate Waco9. Versions of several potential IS or CS genes (indicated by the addition of A or B to the gene name) are due to individual CATMA probes that detect two different transcripts simultaneously on the array, and two quantitative polymerase chain reaction (Q-PCR)-primer sets were made to discriminate between two mRNAs. A, Defense-related (DR) transcripts. Q-PCRs were performed on several transcription factors and on NPR1, PDF1.2, and PR-1, which were not present on the CATMA array. All genes show similar levels of induction in both interactions, confirming the microarray data. Only $P R-1$ and PDF1.2 are more highly expressed in an incompatible interaction but not exclusively induced. B, IS genes. Three genes, IS-01, IS-02, and IS-07, show a modest induction during an incompatible interaction. $\mathbf{C}, \mathrm{CS}$ genes. The majority of genes show a specific differential expression in the Ler-Cala2 (compatible) interaction and are highlighted by underlining; exceptions are CS-04, that seems to be defense-related, and CS-13 and CS-16, showing no differential expression at all. 
regions of the CS genes 1,000 bp upstream of the start codon. Two promoter elements were significantly enriched when all CS genes were analyzed together. The EveningElement (AAAATATCT, $P<10^{-5}$ ) was found once in eight different promoters and is involved in evening-specific transcription (Harmer et al. 2000). The DREB1A/CBF3 element (consensus sequence RCCGACNT, $P<10^{-3}$ ) was found one to three times in six different promoters. Importantly, enrichment for both promoter elements was also found when the 14 initially identified CS genes were analyzed separately. Moreover, analyses of all differentially expressed genes in the compatible or incompatible interaction showed no enrichment for these elements. Separate promoter analysis of the seven CS genes that are responsive to a broad range of abiotic stresses (Table 2) showed that these genes are enriched for more elements. A more significant enrichment was found of the EveningElement $\left(P<10^{-6}\right)$ and DREB1A/CBF3 $\left(P<10^{-4}\right)$ and several other elements, such as the DRE core motif $\left(P<10^{-4}\right)$ (consensus sequence RCCGAC) (Chen et al. 2002), which is a relaxed form of
DREB1A/CBF3, the CBF1 binding site (BS) $\left(P<10^{-3}\right)$ (consensus sequence TGGCCGAC) (Hao et al. 2002) and the Zbox motif $\left(P<10^{-3}\right)$ (consensus sequence ATACGTGT) (Ha and An 1988). Although many CS genes show responsiveness toward $\mathrm{ABA}$, the $\mathrm{ABA}$ responsive element $\mathrm{ABRE}$ (consensus sequence YACGTGGC) (Choi et al. 2000) was not overrepresented and only found once in the promoter of CS20/AtERF\#109. However, nine CS genes contain the ABRElike binding site motif (consensus sequence BACGTGKM) (Shinozaki and Yamaguchi-Shinozaki 2000). The occurrence of the abovementioned binding sites is summarized for all CS genes in Table 3. That CS gene promoters are enriched for DRE or EveningElements suggests that expression during compatible $H$. arabidopsidis interactions is controlled by these elements.

The gene products of AtERF\#029 (CBF1), AtERF\#030 (CBF2), and AtERF\#031 (CBF3) are known to bind the identified DREB/CBF elements (Agarwal et al. 2006) and belong to subclade III-c of the ERF family (Nakano et al. 2006). How-
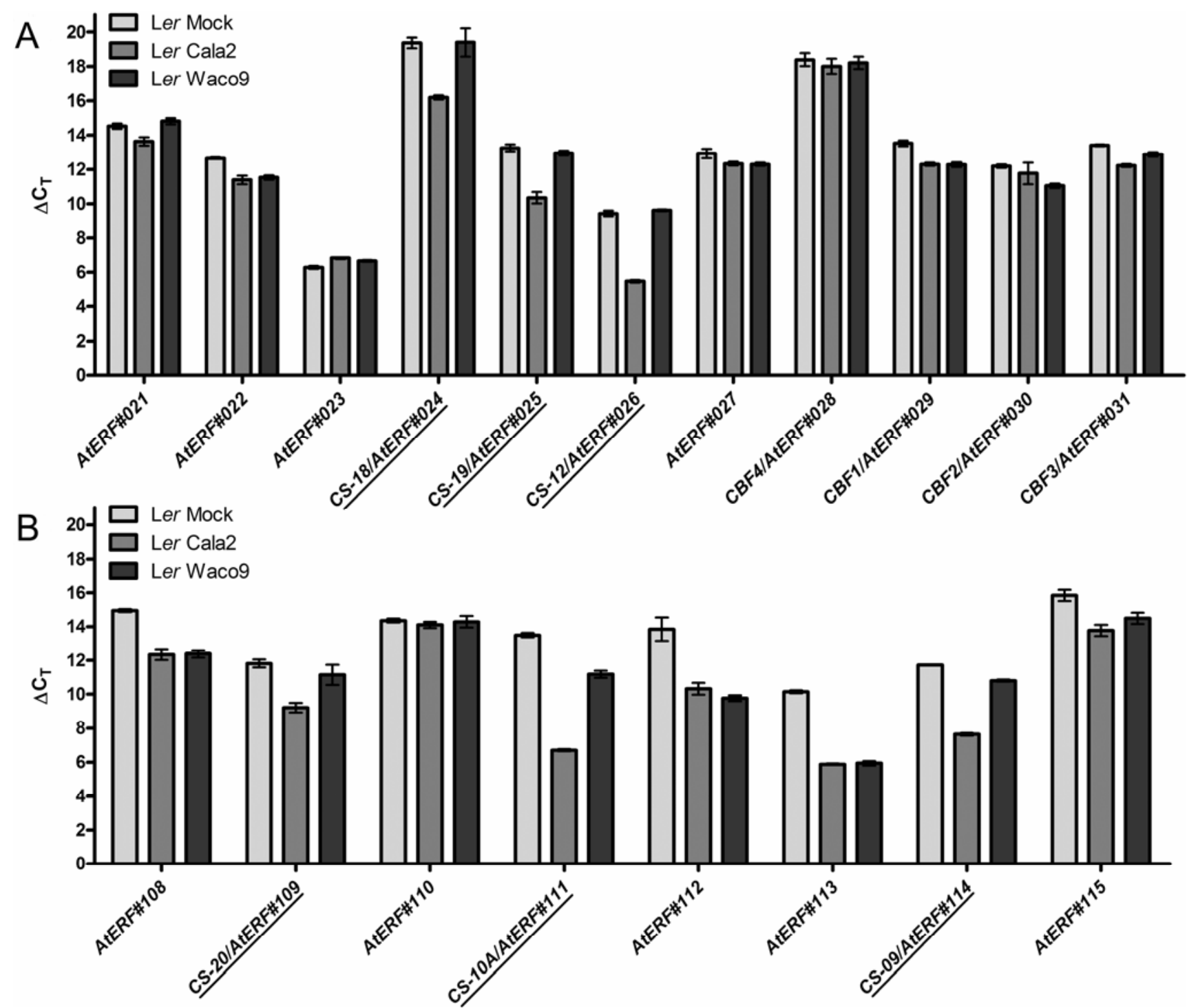

Fig. 4. Relative transcript levels of ethylene response factor (ERF) family members homologous to the identified compatible-specific (CS) ERF transcription factors. Plants were either mock treated or inoculated with a compatible (Cala2) or incompatible (Waco9) Hyaloperonospora arabidopsidis isolate. The error bars are given as standard error of mean and ERF that show induction specific for the compatible interaction (Cala2) are underlined. Note that lower bars represent higher transcript abundance. A, Clade III of the ERF gene-family (Nakano et al. 2006) homologous to CS-12/AtERF\#26. The diagram shows that AtERF\#024 and AtERF\#025 are also specifically induced during a compatible interaction, whereas the other genes are not. B, Differential expression of clade X members of the ERF family homologous to CS-10A, CS-09, and AtERF\#113, which is also induced during incompatible interactions. AtERF\#109 is also a CS gene whereas AtERF\#108, AtERF\#112, and AtERF\#115 are induced in both interactions and, therefore, defense related. 
A

H. arabidopsidis Actin

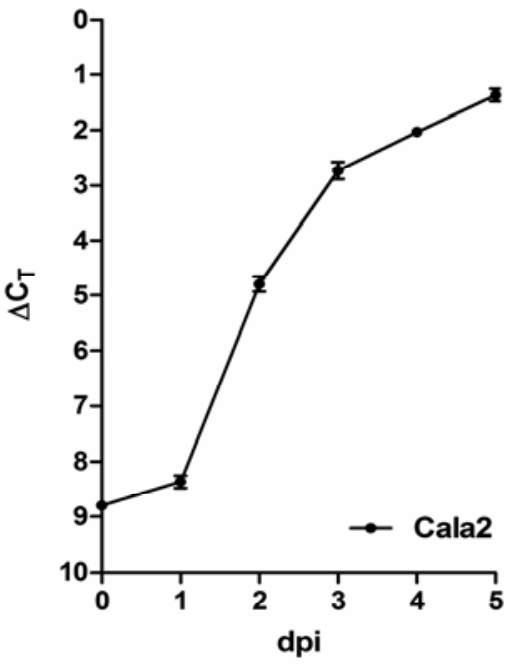

D

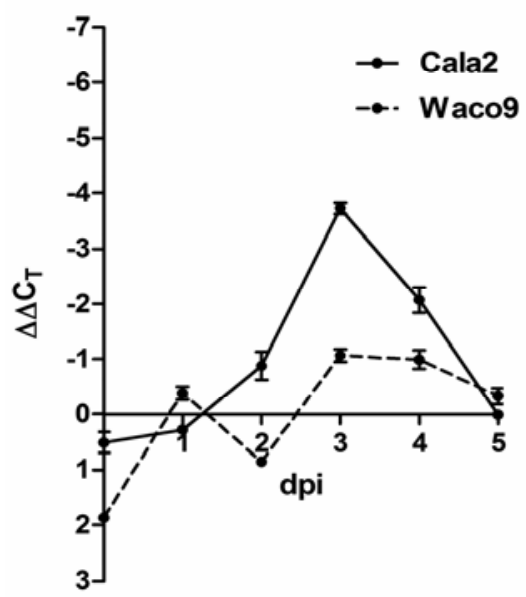

G

CS-12/AtERF\#26

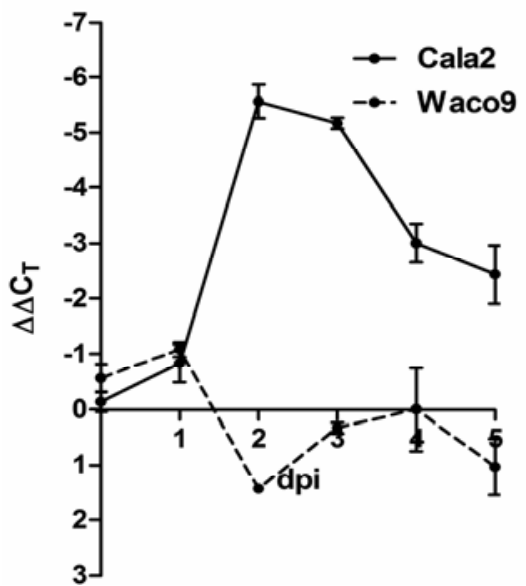

B

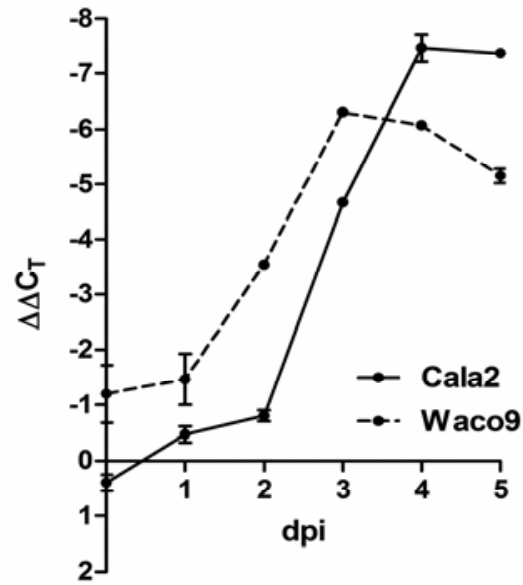

E

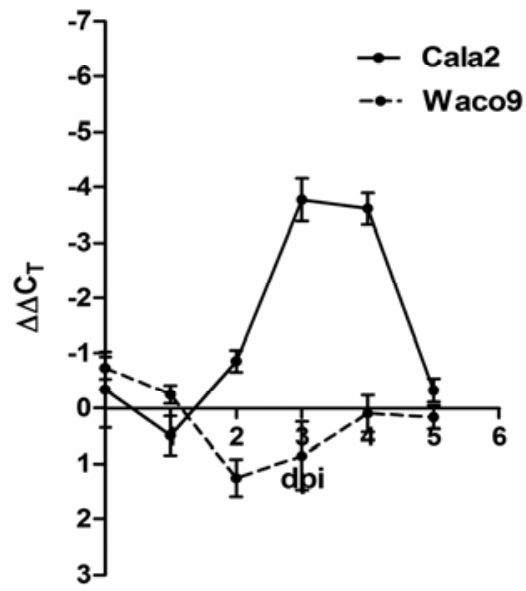

$\mathrm{H}$

CS-19/AtERF\#25

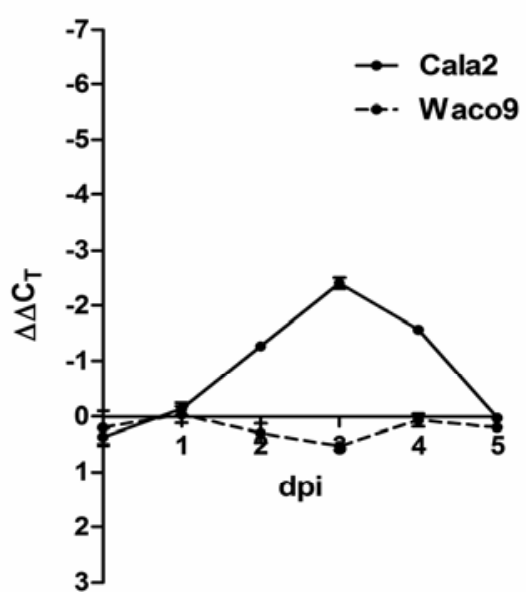

C

DMR6

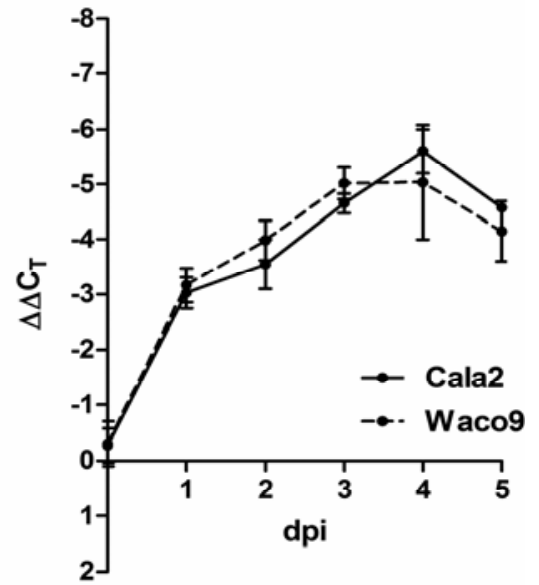

F

CS-08/CIPK25

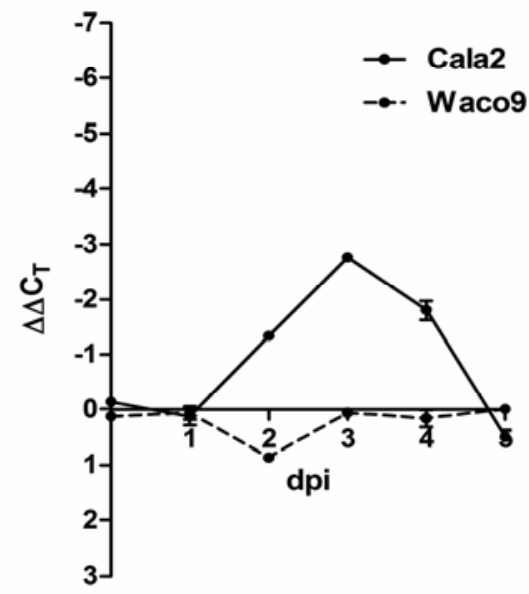

CS-20/At1g10585

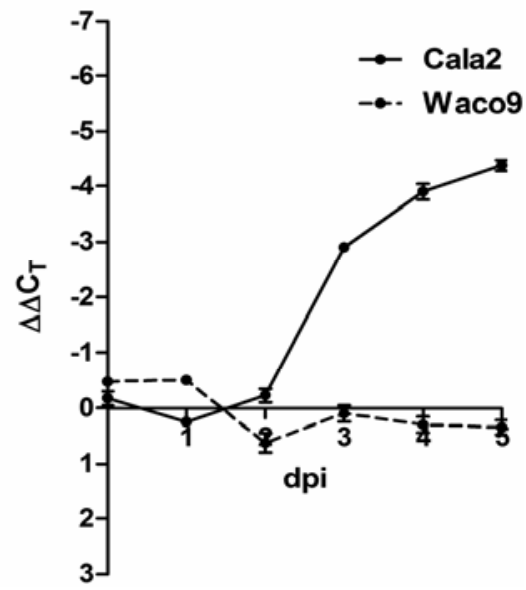

Fig. 5. Temporal expression of three defense-related (DR) and five compatible-specific (CS) genes in a compatible (Cala2) and incompatible (Waco9) interaction. Transcripts levels for all quantitative polymerase chain reaction measurements were normalized for Arabidopsis Act2 (At3g18780) and the mock treatment giving cycle threshold $\left(\Delta \Delta \mathrm{C}_{\mathrm{T}}\right)$ values, except for Hyaloperonospora arabidopsidis Actin levels. The error bars are given as the standard error of mean and the scale is reversed to ease interpretation. A, H. arabidopsidis Actin levels were used as a measure of pathogen growth from 0 to 5 days postinoculation (dpi). The highest growth rate was observed between 1 and $3 \mathrm{dpi}$. B and $\mathbf{C}$, Two DR transcripts were followed in time. $P R-1$ is more highly expressed in an incompatible interaction during early timepoints, indicating a fast induction. Relatively higher transcript levels are observed at 4 and 5 dpi for a compatible interaction. DMR6 transcript levels are very similar for both interactions with identical starting points. D through I, Temporal expression of six CS genes: Xero2, bHLH162, CIPK25, AtERF\#025, AtERF\#26, and At1g10585, respectively Transcript levels are enhanced and peak at 2 to 3 dpi in the compatible interaction whereas this is not observed in an incompatible interaction, except for Atlg10585, that increases in time and follows the increase in pathogen biomass. Interestingly, their specific induction disappears at $5 \mathrm{dpi}$. AtERF\#026 shows a very strong induction already at $2 \mathrm{dpi}$ which is diminished at 5 dpi. 
ever, none of these $\mathrm{CBF}$ genes is induced by downy mildew (Fig. 5A). In contrast, the related genes from subclade III-b, AtERF\#024 (CS-18), AtERF\#025 (CS-19), and AtERF\#026 (CS-12), are activated upon downy mildew infection. The CBF genes AtERF\#024, AtERF\#025, and AtERF\#026 belong to clade III, suggesting that their encoded proteins could have similar functions based on homology of the AP2/ERF domain (Nakano et al. 2006).

The promoters of AtERF\#024 (CS-18), AtERF\#025 (CS-19), and AtERF\#026 (CS-12) do not contain any of the discussed promoter elements (Table 3 ), suggesting that they are regulated in a different way than other CS genes. Moreover, AtERF\#024 (CS-18), AtERF\#025 (CS-19), and AtERF\#026 (CS-12) are not induced by a broad range of abiotic stress conditions according to AtGenExpress data (Table 2), whereas $C B F 1, C B F 12$, and $C B F 13$ are highly induced by cold stress. AtERF\#024 (CS-18), AtERF\#025 (CS-19), and AtERF\#026 (CS-12) become induced during compatible $H$. arabidopsidis infections; therefore, it could be that they control expression of other CS genes with DRE elements in their promoters.

\section{Temporal expression of CS genes during downy mildew infection.}

To study CS gene expression during infection with $H$. arabidopsidis, transcript levels of six CS genes were measured by Q-PCR on inoculation series from 0 to 5 dpi with intervals of

Table 1. Description of compatible- and incompatible-specific genes that have been confirmed by quantitative polymerase chain reaction (Q-PCR) ${ }^{\mathrm{a}}$

\begin{tabular}{|c|c|c|c|c|}
\hline Q-PCR ID & AGI ID & Name & Induced by $^{b}$ & References \\
\hline \multicolumn{5}{|l|}{ IS genes } \\
\hline IS-01 & At1g52400 & BGL1 & JA & Stotz et al. 2000 \\
\hline IS-02 & At1g52410 & Caldesmon related & $\ldots$ & $\ldots$ \\
\hline IS-07 & At1g67865 & Expressed protein & $\ldots$ & $\ldots$ \\
\hline \multicolumn{5}{|l|}{ CS genes } \\
\hline CS-01 & At1g01470 & LEA14 & HL, DH, LT, salt & Kimura et al. 2003 \\
\hline CS-02 & At1g20440 & COR47 & LT & Nylander et al. 2001 \\
\hline CS-03 & At1g51090 & Heavy-metal associated & $\ldots$ & $\ldots$ \\
\hline CS-05 & At3g50970 & Xero $2 /$ LTI30 & LT & Nylander et al. 2001 \\
\hline CS-06 & At4g19230 & CYP707A1 & $\mathrm{ABA}$ & Okamoto et al. 2006; Kushiro et al. 2004 \\
\hline CS-07 & At4g20970 & bHLH162 & $\ldots$ & Bailey et al. 2003 \\
\hline CS-08 & At5g25110 & CIPK25 & Calcium & Kolukisaoglu et al. 2004 \\
\hline CS-09 & At5g61890 & AtERF\#114 & $\ldots$ & Nakano et al. 2006 \\
\hline CS-10A & At5g64750 & AtERF\#111/ABR1 & ABA, LT, DH, salt & Nakano et al. 2006; Pandey et al. 2005 \\
\hline CS-11 & Atlg15010 & Expressed protein & $\ldots$ & $\ldots$ \\
\hline CS-12 & At1g63040 & AtERF\#026 & $\ldots$ & Nakano et al. 2006 \\
\hline CS-14 & At4g30650 & LTI6A/RCI2AS & LT, ABA, DH, salt & $\begin{array}{l}\text { Capel et al. 1997; Medina et al. 2001, 2005; } \\
\text { Mitsuya et al. } 2005\end{array}$ \\
\hline CS-15 & At2g42530 & COR15b & $\mathrm{LT}, \mathrm{ABA}$ & Wilhelm and Thomashow 1993 \\
\hline CS-17 & At2g15890 & Expressed protein & $\ldots$ & $\ldots$ \\
\hline CS-18 & At2g36450 & AtERF\#024 & $\ldots$ & $\ldots$ \\
\hline CS-19 & At5g52020 & AtERF\#025 & $\ldots$ & $\ldots$ \\
\hline CS-20 & At4g34410 & AtERF\#109 & $\ldots$ & $\ldots$ \\
\hline
\end{tabular}

${ }^{\text {a }}$ For a selection of genes, for which the Q-PCR- and Arabidopsis Genome Initiative (AGI) IDs are given, their induction is described in literature. In contrast to the incompatible-specific (IS) genes, many of the compatible-specific (CS) genes are induced by various abiotic stress responses such as low temperature, dehydration, high salt and abscisic acid (ABA).

${ }^{\mathrm{b}} \mathrm{JA}=$ jasmonic acid, $\mathrm{HL}=$ high light, $\mathrm{DH}=$ dehydration, $\mathrm{LT}=$ low temperature and $\mathrm{ABA}=$ abscisic acid.

Table 2. AtGenExpress microarray data of compatible-specific (CS) genes ${ }^{\mathrm{a}}$

\begin{tabular}{|c|c|c|c|c|c|c|}
\hline Q-PCR ID & Cold & $\begin{array}{c}\text { Osmotic } \\
\text { (300 } \mathrm{mM} \text { mannitol) }\end{array}$ & $\begin{array}{c}\text { Salt } \\
(150 \mathrm{mM} \mathrm{NaCl})\end{array}$ & $\begin{array}{c}\text { Drought } \\
\text { (dry air stream) }\end{array}$ & $\begin{array}{c}\text { Wounding } \\
\text { (leaf punctuation) }\end{array}$ & $10 \mu \mathrm{M}$ ABA \\
\hline CS-01 & ++++ & ++++ & +++ & ++ & +++ & ++++ \\
\hline CS-02 & ++++ & ++++ & ++++ & ++ & ++++ & ++++ \\
\hline CS-03 & ++++ & ++ & ++ & 0 & ++ & 0 \\
\hline CS-05 & ++++ & ++++ & +++ & + & +++ & ++++ \\
\hline$C S-10 A$ & $\mathrm{np}$ & $\mathrm{np}$ & $\mathrm{np}$ & $\mathrm{np}$ & $\mathrm{np}$ & $\mathrm{np}$ \\
\hline$C S-14$ & $---1++++$ & $++/--$ & +++ & $+1--$ & $++++/-$ & ++ \\
\hline$C S-15$ & ++++ & +++ & +++ & $++/--$ & $++/--$ & +++ \\
\hline CS-06 & 0 & 0 & 0 & 0 & 0 & +++ \\
\hline CS-07 & $\mathrm{np}$ & $\mathrm{np}$ & $\mathrm{np}$ & np & $\mathrm{np}$ & $\mathrm{np}$ \\
\hline CS-08 & ++ & + & 0 & 0 & 0 & + \\
\hline CS-09 & 0 & 0 & 0 & 0 & 0 & 0 \\
\hline$C S-11$ & 0 & 0 & 0 & 0 & ++ & 0 \\
\hline$C S-12$ & 0 & 0 & 0 & 0 & 0 & 0 \\
\hline CS-17 & --- & $+/--$ & -- & $-1++$ & $+/--$ & -- \\
\hline CS- 18 & 0 & 0 & 0 & 0 & 0 & 0 \\
\hline$C S-19$ & 0 & 0 & 0 & 0 & + & 0 \\
\hline$C S-20$ & 0 & 0 & 0 & 0 & ++ & 0 \\
\hline
\end{tabular}

${ }^{a}$ Differential expression of 17 CS genes was investigated with the visualization tool of AtGenExpress in the abiostress dataset to find inducers or repressors of them. CS-07 (At4g20970) and CS-10A (At5g64750) are not present in the AtGenExpress dataset and, therefore, are given a not present (np) classification. All measurements were background corrected and the induction or repression was classified according to the following rules: 0 to $500=0$ (no difference), 500 to $1,000=+, 1,000$ to $5,000=++, 5,000$ to $10,000=+++$, and $>10,000=++++$ for induction; and 0 to $-500=0$ (no difference), -500 to $-1,000=-,-1,000$ to $-5,000=--,-5,000$ to $-10,000=---$, and $<-10,000=----$ for repression. Some genes have gained double classifications indicating that they are first repressed and then induced in time (e.g., - - -/++++) or vice versa (e.g., ++++/-). Q-PCR = quantitative polymerase chain reaction and $\mathrm{ABA}=$ abscisic acid. 
1 day. Pathogen colonization was monitored by measuring $H$. arabidopsidis Actin2 transcript levels. The highest growth rate of the pathogen was observed between 1 and 3 dpi and the growth rate declined at 4 to $5 \mathrm{dpi}$ (Fig. 5A), at approximately the same time that sporulation starts. In addition, expression of $P R-1$ and DMR6 was studied because those genes are highly induced in both the compatible and incompatible interaction (Fig. 5B and C). The defense-related gene PR-1 is more highly induced in the incompatible interaction than in the compatible interaction at early timepoints (1 to $3 \mathrm{dpi}$ ). DMR6 is similarly induced in both interactions (1 to $3 \mathrm{dpi}$ ). Transcript levels of these two defense-related genes decline in the incompatible interaction after 3 dpi. This is expected because the early defense responses have arrested $H$. arabidopsidis growth already at 1 to 2 dpi. In the compatible interaction, where pathogen growth is abundant at later stages of the infection ( 4 to $5 \mathrm{dpi}$ ), transcript levels of the defense-related genes are higher (Fig. 5B and C).

All six tested CS genes are induced only during the compatible interaction and not during an incompatible interaction (Fig. 5D through I), although a slight induction is observed for CS-05 (Xero2) at 3 and 4 dpi during an incompatible interaction (Fig. 5D). The CS genes show a similar pattern in time that is different from that of the defense-related genes, except for CS-20 (Fig. 5I) that is similar in expression to $P R-1$ in the compatible interaction and to the increase in pathogen biomass (Fig. 5A and B). In contrast, CS-05 (Xero2), CS-07 (bHLH162), CS-08 (CIPK25), and CS-19 (AtERF\#025) are most highly expressed at 3 dpi and their transcript levels decline after this timepoint, to reach the same level as in mock-treated plants at 5 dpi. Remarkably, both pathogen growth and CS gene expression are highest at $3 \mathrm{dpi}$ but when, at 4 to $5 \mathrm{dpi}, H$. arabidopsidis starts sporulating, their specific induction completely disappears. CS-12 (AtERF\#026) reaches its peak level already at 2 dpi with a much stronger induction than the other CS genes. This induction also declines toward 5 dpi but does not completely return to expression levels of mock-treated plants. The expression patterns of the CS genes show that they are truly specifically induced during a compatible interaction and that their highest transcript levels are obtained when $H$. arabidopsidis has it largest growth rate at 2 to $3 \mathrm{dpi}$.
Isolate-specific induction of $\mathrm{CS}$ genes.

The induction of CS genes during compatible Cala2 interactions but not during incompatible Waco9 interactions indicates that CS gene expression is related to pathogen colonization and not to defense. However, it could also be due to specific differences between the isolates. Although the identified CS genes are not induced during incompatible Waco 9 interactions, they may become induced during incompatible Cala2 or compatible Waco9 interactions. To test this, Arabidopsis Ws-4 was inoculated with Waco9 and Cala2 and expression of CS genes analyzed at $3 \mathrm{dpi}$. In these interactions, Waco9 is compatible and Cala2 incompatible. None of the CS genes become induced during the incompatible Cala2 interaction (Fig. 6A). This demonstrates that CS gene induction is due to colonization by Cala2. Half of the CS genes showed induction in the compatible Waco9 interaction, demonstrating that both isolates induce expression of these genes during compatible and not during incompatible interactions. The other half of the CS genes was not induced during the compatible Waco9 interaction; of these, CS-01 and CS-17 showed no induction, CS-02 and CS-05 showed slightly lower expression in both interactions, and CS08, CS-14, CS-15, and CS-18 showed lower expression levels in the compatible Waco9 interaction. There are different explanations possible for the different expression patterns in the Ler and Ws-4 interactions. It may be that Waco9 does not induce some of the CS genes or even downregulates them. Alternatively, induction could be low, thereby being difficult to detect (e.g., the CS-01 and CS-17 genes may not be induced in the Arabidopsis accession Ws-4, whereas they are induced in Ler, regardless of the $H$. arabidopsidis isolate used). For three CS genes, CS-08 (CIPK25), CS-14 (LTI6A/RCI2AS), and CS-15 $(C O R 15 b)$, these different possibilities were sorted out. Ler eds1-2, Col eds1, and Ws eds1 plants were inoculated with both Cala2 and Waco9. Due to mutation of EDS1, all interactions were compatible. CS-08, CS-14, and CS-15 were specifically induced by Cala2 and not by Waco9, regardless of the Arabidopsis accession (Fig. 6B through D). CS-09 was induced by both isolates as expected and confirms the data from Figures 4B and 6A. Interestingly, the observed minor downregulation of CS-08, CS-14, and CS-15 in Waco9-challenged

Table 3. Promoter elements in compatible-specific (CS) genes ${ }^{\mathrm{a}}$

\begin{tabular}{|c|c|c|c|c|c|c|}
\hline Genes & ABRE-like & DRE core & DREB1A/CBF3 & CBF1 & EveningElement & Z-box \\
\hline \multicolumn{7}{|l|}{ Broad } \\
\hline CS- 01 & 1 & 3 & 2 & $\ldots$ & 1 & 1 \\
\hline CS- 02 & 1 & 3 & 2 & $\ldots$ & $\ldots$ & 1 \\
\hline CS- 03 & 1 & 2 & 2 & $\ldots$ & 1 & $\ldots$ \\
\hline CS- 05 & $\ldots$ & 3 & 3 & 1 & 1 & 1 \\
\hline$C S-10 A$ & 1 & 3 & $\ldots$ & $\ldots$ & $\ldots$ & $\ldots$ \\
\hline CS-14 & $\ldots$ & 1 & 1 & $\ldots$ & 1 & $\ldots$ \\
\hline$C S-15$ & 2 & 2 & 2 & 1 & 1 & $\ldots$ \\
\hline \multicolumn{7}{|l|}{ Specific } \\
\hline CS-06 & 2 & $\ldots$ & $\ldots$ & $\ldots$ & 1 & $\ldots$ \\
\hline CS- 07 & $\ldots$ & $\ldots$ & $\ldots$ & $\ldots$ & 1 & $\ldots$ \\
\hline CS-08 & 1 & $\ldots$ & $\ldots$ & $\ldots$ & $\ldots$ & $\ldots$ \\
\hline CS-09 & $\ldots$ & 2 & $\ldots$ & $\ldots$ & $\ldots$ & $\ldots$ \\
\hline$C S-11$ & 1 & $\ldots$ & $\ldots$ & $\ldots$ & $\ldots$ & $\ldots$ \\
\hline$C S-12$ & $\ldots$ & $\ldots$ & $\ldots$ & $\ldots$ & $\ldots$ & $\ldots$ \\
\hline CS -17 & $\ldots$ & $\ldots$ & $\ldots$ & $\ldots$ & 1 & $\ldots$ \\
\hline CS- 18 & $\ldots$ & $\ldots$ & $\ldots$ & $\ldots$ & $\ldots$ & $\ldots$ \\
\hline CS -19 & $\ldots$ & $\ldots$ & $\ldots$ & $\ldots$ & $\cdots$ & $\ldots$ \\
\hline$C S-20$ & 1 & $\ldots$ & $\ldots$ & $\ldots$ & $\ldots$ & $\ldots$ \\
\hline
\end{tabular}

${ }^{a}$ Classifications for induction were combined with the presence of the number of overrepresented promoter elements as indicated by Athena. A subset of seven CS genes (Broad) responded toward a broad range of inducers such as cold, osmotic stress, salt, and abscisic acid and their promoters have, in general, combinations of the ABRE-like and dehydration-responsive element/C-repeat binding factor (DREB1A/CBF3) motif. Other CS genes (Specific) showed a specific induction or a modest differential expression as shown by AtGenExpress. Note that CS-07 (At4g20970) and CS-10 (At5g64750) are not present in the AtGenExpress dataset, but CS-10 is also induced by abiotic stress according to literature. CS-07 (bHLH162), CS-12 (AtERF\#026), CS-16 (AtERF\#024), and CS-17 (AtERF\#025) are only differentially expressed (DE) by compatible Hyaloperonospora arabidopsidis and do not hold ABRE-like or DRE core elements in their promoters. 
Ws-4, Ler eds1-2, and Col eds1 (Fig. 6A through C) plants was not seen in Ws eds 1 plants (Fig. 6D). We conclude that several CS genes are clearly induced by specific $H$. arabidopsidis isolates, suggesting that host transcription is differentially activated in an isolate-specific manner.

\section{T-DNA lines disrupted in CS genes.}

To verify the requirement of the genes listed in Supplementary Table S2 for susceptibility to downy mildew, corresponding sequence-tagged insertion mutants were investigated. Development of pathogen growth was monitored in time by measuring the level of sporulation as well as the number of days it takes $H$. arabidopsidis to start sporulating. No T-DNA lines were available for CS-01 (LEA14) and CS-18 (AtERF\#024). Unfortunately, none of the T-DNA insertion mutants showed significant alterations in disease susceptibility. The absence of observable phenotypes could be due to redundant roles of several CS genes (e.g., the three homologous ERF from clade IIIb). Moreover, the available T-DNA lines were all in the Col-0 accession (with the exception of FLAG_486C09 [Ws-4]) and, therefore, could not be tested with the Cala2 isolate. All T-DNA lines were tested with the compatible Waco9 isolate. Because only half of the CS genes become induced by Waco9 in Ws-4 (Fig. 6A), it is possible that these CS genes are not involved in compatible Waco9 interactions (e.g., CS-8, CS-14, and CS-15) (Fig. 6B through D) and, hence, give no phenotype when disrupted.

\section{DISCUSSION}

Arabidopsis genes were identified that are differentially expressed only during compatible but not during incompatible interactions with the downy mildew pathogen $H$. arabidopsidis. This is in contrast to the majority of genes that show induction or repression in both interactions upon $H$. arabidopsidis inoculation. Arrays were hybridized with probes derived from aboveground parts at 3 dpi. Although a convenient approach, it potentially harbors the risk that local mRNA signals due to pathogen invasion are averaged out and become too small to be detected.

Many genes that are differentially expressed in both interactions have been associated with plant defense, and are likely activated due to a general plant response upon pathogen recognition (Maleck et al. 2000). The defense-related genes $P R-1$ and DMR6 were more highly induced at early timepoints of infection during the incompatible interaction with Waco9, indicating that $R$-gene-mediated responses (triggered by RPP5) are faster in general. After 3 dpi, pathogen growth was fully arrested
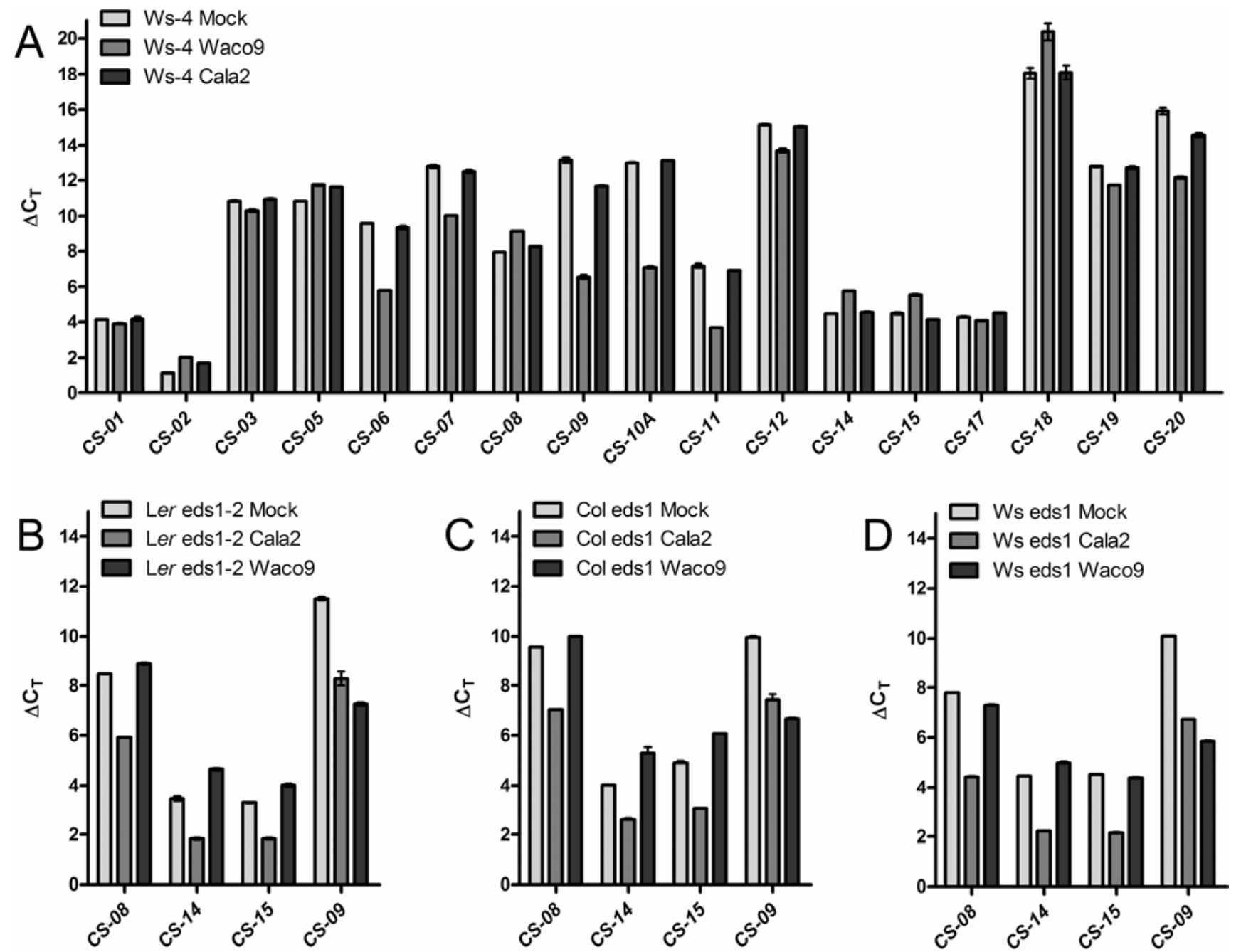

Fig. 6. Relative transcript abundance of compatible-specific (CS) genes 3 days postinoculation in different Arabidopsis accessions inoculated with different isolates. Note that a lower bar indicates higher transcript abundances in all diagrams and that all measurements were normalized for Arabidopsis Act2-levels (At3g18780). The error bars are given as standard error of mean. A, Ws-4 plants were i) mock inoculated, ii) inoculated with the compatible isolate Waco9, or iii) inoculated with the incompatible isolate Cala2. Relative expression of CS-08, CS-09, CS-14, and CS-15 was analyzed by quantitative polymerase chain reaction in B, Ler eds1-2; C, Col eds1; and D, WS eds1 plants, either mock treated or inoculated with Cala2 or Waco9. 
in the incompatible interaction and defense related transcript levels declined. In the compatible interaction, on the other hand, pathogen growth was exponential and nonspecific defense responses were triggered, resulting in higher transcript levels at later stages of infection. These quantitative differences have also been found for other plant-pathogen interactions ( $\mathrm{Li}$ et al. 2006a; Tao et al. 2003) and support the view that $R$-gene-mediated responses amplify MAMP- or PAMP-triggered responses (Jones and Dangl 2006), resulting in the transcriptional activation of a similar set of defense-related genes. In contrast, some CS genes were highest expressed at approximately 2 to $3 \mathrm{dpi}$ strictly in the compatible interaction, and expression levels did not follow the increase in $H$. arabidopsidis biomass (except Atlg10585) as the defense-related transcripts do. This clearly indicates that CS- and defense-related genes are differently regulated. However, not all identified CS genes were followed in time and, therefore, we cannot rule out the possibility that some are differentially expressed in the incompatible interaction before 3 dpi.

Based on publicly available microarray data, it was found that most CS genes are responsive to a broad range of abiotic stress conditions such as cold, salinity, drought, wounding, and ABA, suggesting that compatible $H$. arabidopsidis infections provoke an abiotic stress-like response. This could be the result of absorption of water and nutrients by the pathogen. One would expect that water and nutrient uptake increases with pathogen biomass. However, CS gene expression does not increase with $H$. arabidopsidis biomass but was most highly expressed at 2 to $3 \mathrm{dpi}$. Promoter analyses of all CS genes revealed an overrepresentation of the DREB1A/CBF3 element and the EveningElement involved in evening-specific transcription (Harmer et al. 2000). The ABRE-like element (Shinozaki and Yamaguchi-Shinozaki 2000) was slightly below the significance threshold but was present in nine CS genes, which is interesting because many $\mathrm{CS}$ genes are $\mathrm{ABA}$ responsive. The overrepresentation of promoter motifs, or presence in the case of the ABRE-like element, is in good agreement with the expression of CS genes during abiotic stress conditions.

CS-12 (AtERF\#026), CS-18 (AtERF\#024), and CS-19 (AtERF\#025) did not show responsiveness to different abiotic stress conditions according to AtGenExpress, and none of the discussed promoter elements were present in their promoters. These three genes belong to subclade III-b of the ERF and could be involved in the transcriptional regulation of other CS genes containing DRE-like elements, similarly to what has been described for members of subclade III-c. The subclade III-c members ( $C B F 1, C B F 2$, and $C B F 3)$ are induced by low temperature and activate transcription of genes with DRE elements in their promoters (Gilmour et al. 1998, 2004). Interestingly, cold induction of these three $C B F$ genes is controlled by the circadian clock (Fowler et al. 2005) and links circadian rhythmicity with the transcriptional activation of genes containing DRE elements in their promoters. However, $C B F 1$, $C B F 2$, and $C B F 3$ did not show induction during $H$. arabidopsidis infections and it could be that ERF from subclade III-b activate the induction of CS genes containing DRE(-like) and EveningElements in their promoters during compatible downy mildew infections.

Several CS genes are responsive to ABA and contain ABRElike elements in their promoters, suggesting a role for $\mathrm{ABA}$ in compatible $H$. arabidopsidis interactions. CS-6 (CYP707A1) belongs to the ABA 8'-hydroxylases and is involved in catabolism of ABA and could dampen ABA levels (Kushiro et al. 2004; Okamoto et al. 2006). A similar observation was made for CS10A (AtERF\#111/ABR1), which is a transcription factor serving as repressor of ABA-regulated gene expression (Pandey et al. 2005). Induction of these genes could lower endogenous ABA levels or ABA sensitivity. CS-08 (CIPK25) is probably involved in calcium signaling, which could be involved in various processes such as stomatal closure (Klusener et al. 2002). Recently, it was shown that ABA plays a role in Arabidopsis susceptibility to Pseudomonas syringae (de Torres-Zabala et al. 2007). P. syringae virulence factors specifically manipulate the ABA biosynthetic pathway and response machinery. Enhanced ABA levels were detected during bacterial growth and ABA hypersensitive mutants showed enhanced susceptibility. Moreover, alterations in ABA levels are not just a physiological response because in planta expression of the bacterial effector AvrPtoB increased ABA levels (de Torres-Zabala et al. 2007). There could be a role for ABA in susceptibility to H. arabidopsidis. The ABA-deficient mutant abal-1 showed partial resistance to compatible $H$. arabidopsidis isolates; however, ABA insensitivity had no effect on virulence (Mauch-Mani and Mauch 2005; Mohr and Cahill 2003), suggesting that ABA levels are important for $H$. arabidopsidis virulence whereas a functional ABA signaling cascade is not. Responsiveness to ABA was found for eight CS genes according to AtGenExpress data. However, many of the defense-related genes also contain ABRE(-like) elements. Therefore, genes responsive to ABA are not specific for a compatible interaction.

Previous findings showed that there is crosstalk between cold and osmotic stress pathways. Genes transcriptionally activated during cold stress are regulated by DRE elements in their promoters and during osmotic stress by ABRE elements, which are ABA dependent (Shinozaki and YamaguchiShinozaki 2000; Yamaguchi-Shinozaki and Shinozaki 2006). A model was proposed for RD29A (also known as COR78 or LTI78) in which DRE and ABRE elements in the promoter of this gene are required for the subsequent stress tolerance. Several CS genes (CS-01, CS-02, CS-03, CS-10A, and CS-15) hold combinations of ABRE-like and DRE elements such as DRE-core, DREB1a/CBF, or CBF1. It could be that ABAresponsive $C S$ genes are $C S$ expressed because their promoters contain this combination of elements.

CS genes could primarily respond to the physiological consequences of $H$. arabidopsidis infections (e.g., due to water and nutrient loss). Alternatively, the pathogen could secrete effectors targeting the expression of CS genes. Three CS genes, CS-8 (CIPK25), CS-14 (LTI6A/RCI2AS), and CS-15 $(C O R 15 b)$, become specifically induced by compatible interactions with the Cala2 isolate but not in interactions with the Waco9 isolate. This suggests that their expression is induced by pathogen-produced effectors or compounds. How this would aid the pathogen in growth or nutrient retrieval is unclear. It may be that the CS proteins enhance nutrient production of the host, or they could lower plant defenses by mimicking a certain type of abiotic stress. Knock-out and overexpressing lines of CS genes are being studied to elucidate their role in compatible $H$. arabidopsidis infections and disease susceptibility in general.

\section{MATERIALS AND METHODS}

Growth and inoculation of Arabidopsis.

Arabidopsis plants were grown on potting soil for 11 days (Primasta, Asten, The Netherlands) in a growth chamber (Snijders Scientific, Tilburg, The Netherlands) at $22^{\circ} \mathrm{C}$ with 16 $\mathrm{h}$ of light (approximately $100 \approx \mathrm{mol}$ photons $\mathrm{m}^{-2} \mathrm{~s}^{-1}$ ) and a relative humidity of $70 \%$. Plants were subsequently mock inoculated or treated with Cala 2 or Waco 9 at 50 sporangia $\mu 1^{-1}$ using a spray gun. After inoculation, plants were allowed to dry for $2 \mathrm{~h}$ and subsequently incubated under a sealed lid with $100 \%$ relative humidity in a growth chamber at $16^{\circ} \mathrm{C}$ with $9 \mathrm{~h}$ of light (approximately $100 \mu \mathrm{mol}$ photons $\mathrm{m}^{-2} \mathrm{~s}^{-1}$ ). 


\section{RNA extraction.}

RNA was extracted with a RNeasy kit (Qiagen, Venlo, The Netherlands) and treated with the RNase-free DNase set (Qiagen), yielding approximately $50 \mu \mathrm{g}$ of RNA per isolation. The quantity of RNA was measured using an UVmini-1240 spectrophotometer (Shimadzu, Kyoto, Japan) and the quality with the Bioanalyzer 2100 (Agilent Technologies, Palo Alto, CA, U.S.A.) using the RNA 6000 Nano Assay kit (Agilent Technologies).

\section{CATMA arrays.}

Microarray analysis was performed with CATMA version 2 arrays (complete Arabidopsis transcriptome microarray) (Allemeersch et al. 2005; Hilson et al. 2004). CATMA version 2 contained 24,411 gene-specific tags (GST). The GST (which are between 150 and $500 \mathrm{bp}$ in length and show no more than $70 \%$ identity with any other sequence in the genome) were spotted on GAPSII glass slides (Corning Incorporated, Acton, MA, U.S.A.) using a BioRobotics Microgrid II TAS spotter (Genomic Solutions, Ann Arbor, MI, U.S.A.) and cross-linked for $4 \mathrm{~h}$ at $80^{\circ} \mathrm{C}$. Detailed information about CATMA and database access can be found at online (Crowe et al. 2003).

\section{Labeling, hybridization, and scanning.}

The complete microarray procedure used in this article has been extensively described before (de Jong et al. 2006). Briefly, mRNA from isolated RNA was amplified with the MessageAmp II aRNA kit (Ambion, Austin, TX, U.S.A.). Amplified mRNA was used as template to synthesize modified cDNA with SuperScript III reverse transcriptase (Invitrogen, Carlsbad, CA, U.S.A.) and random nonamers (Gene Link, Westchester County, NY, U.S.A.) with incorporation of 5-(3aminoallyl)-dUTP (Ambion). Obtained cDNA was labeled with either $\mathrm{Cy} 3$ or $\mathrm{Cy} 5$ monoreactive dye (Amersham, Buckinghamshire, U.K.) and incorporation was determined using an UVmini-1240 spectrophotometer at 550 or $650 \mathrm{~nm}$, respectively. The probes were hybridized overnight on CATMA arrays and scans were made using a ScanArray Express HT (PerkinElmer, Wellesley, MA, U.S.A.). Spot intensities of the scans were determined by ImaGene software version 6.5.1 (BioDiscovery, El Segundo, CA, U.S.A.).

\section{Statistics.}

Analysis of spot intensities from the CATMA arrays and applied statistics were performed as described before (de Jong et al. 2006). Biological replicates of the mock-treated and Waco9- or Cala2-inoculated materials were analyzed separately to visualize the variation between them. Differentially expressed (DE) genes in the Cala2 or Waco9 interactions at 3 dpi were selected based on $-0.75 \geq \mathrm{M} \geq 0.75\left(\mathrm{M}=\log _{2}[\mathrm{~A} / \mathrm{B}]\right)$ and $q$ values $<0.05$. Pearson correlations were calculated from the average $M$ values ( $\log _{2}$ ratios) obtained from DE genes present in the overlay between the interactions.

\section{Microarray data.}

The microarray data discussed in this publication have been deposited in the National Center for Biotechnology Information Gene Expression Omnibus (GEO) (Barrett et al. 2005; Edgar et al. 2002) and are accessible through GEO series record GSE14946.

\section{Q-PCR.}

Extracted RNA from biological replicates for each interaction (mock, Cala2, or Waco9) was pooled in equal amounts and cDNA was subsequently synthesized with SuperScript III reverse transcriptase (Invitrogen) and oligo(dT) $)_{15}$ (Promega Corp., Madison, WI, USA). Timeseries for each interaction from 0 dpi to 5 dpi with 1 day intervals were made from pooled RNA from three biological replicates per timepoint. Cycle thresholds $\left(\mathrm{C}_{\mathrm{T}}\right)$ were determined in triplicate per transcript by the ABI PRISM 7700 sequence detection system (Applied Biosystems, Foster City, CA, U.S.A.) using SYBR Green I (Applied Biosystems) as reporter dye. Primer sets with amplicons between 99 and 101 bases for the $C_{T}$ determination of all transcripts discussed in this article are given in the supplementary material (Supplementary Table S3).

\section{ACKNOWLEDGMENTS}

We thank the following people from our microarray facility for their general help and providing us with the CATMA arrays: F. L. H. Menke, S. C. Mithoe, and A. Andel. This research was funded by a VIDI innovational research grant from The Netherlands Organization for Scientific Research (NWO) to Guido Van den Ackerveken and by the Centre for BioSystems Genomics (CBSG), which is part of the Netherlands Genome Initiative.

\section{LITERATURE CITED}

Agarwal, P. K., Agarwal, P., Reddy, M. K., and Sopory, S. K. 2006. Role of DREB in abiotic and biotic stress tolerance in plants. Plant Cell Rep. 25:1263-1274.

Allemeersch, J., Durinck, S., Vanderhaeghen, R., Alard, P., Maes, R., Seeuws, K., Bogaert, T., Coddens, K., Deschouwer, K., Van Hummelen, P., Vuylsteke, M., Moreau, Y., Kwekkeboom, J., Wijfjes, A. H., May, S., Beynon, J., Hilson, P., and Kuiper, M. T. 2005. Benchmarking the CATMA microarray. A novel tool for Arabidopsis transcriptome analysis. Plant Physiol. 137:588-601.

Ayliffe, M. A., Roberts, J. K., Mitchell, H. J., Zhang, R., Lawrence, G. J., Ellis, J. G., and Pryor, T. J. 2002. A plant gene up-regulated at rust infection sites. Plant Physiol. 129:169-180.

Bailey, P. C., Martin, C., Toledo-Ortiz, G., Quail, P. H., Huq, E., Heim, M. A., Jakoby, M., Werber, M., and Weisshaar, B. 2003. Update on the basic helix-loop-helix transcription factor gene family in Arabidopsis thaliana. Plant Cell 15:2497-2502.

Barrett, T., Suzek, T. O., Troup, D. B., Wilhite, S. E., Ngau, W. C., Ledoux, P., Rudnev, D., Lash, A. E., Fujibuchi, W., and Edgar, R. 2005. NCBI GEO: Mining millions of expression profiles-database and tools. Nucleic Acids Res. 33:D562-566.

Capel, J., Jarillo, J. A., Salinas, J., and Martinez-Zapater, J. M. 1997. Two homologous low-temperature-inducible genes from Arabidopsis encode highly hydrophobic proteins. Plant Physiol. 115:569-576.

Chen, W., Provart, N. J., Glazebrook, J., Katagiri, F., Chang, H. S., Eulgem, T., Mauch, F., Luan, S., Zou, G., Whitham, S. A., Budworth, P. R., Tao, Y., Xie, Z., Chen, X., Lam, S., Kreps, J. A., Harper, J. F., SiAmmour, A., Mauch-Mani, B., Heinlein, M., Kobayashi, K., Hohn, T., Dangl, J. L., Wang, X., and Zhu, T. 2002. Expression profile matrix of Arabidopsis transcription factor genes suggests their putative functions in response to environmental stresses. Plant Cell 14:559-574.

Chisholm, S. T., Coaker, G., Day, B., and Staskawicz, B. J. 2006. Hostmicrobe interactions: Shaping the evolution of the plant immune response. Cell 124:803-814.

Choi, H., Hong, J., Ha, J., Kang, J., and Kim, S. Y. 2000. ABFs, a family of ABA-responsive element binding factors. J. Biol. Chem. 275:1723-1730.

Crowe, M. L., Serizet, C., Thareau, V., Aubourg, S., Rouze, P., Hilson, P., Beynon, J., Weisbeek, P., van Hummelen, P., Reymond, P., Paz-Ares, J., Nietfeld, W., and Trick, M. 2003. CATMA: A complete Arabidopsis GST database. Nucleic Acids Res. 31:156-158.

de Jong, M., van Breukelen, B., Wittink, F. R., Menke, F. L., Weisbeek, P. J., and Van den Ackerveken, G. 2006. Membrane-associated transcripts in Arabidopsis; their isolation and characterization by DNA microarray analysis and bioinformatics. Plant J. 46:708-721.

de Torres-Zabala, M., Truman, W., Bennett, M. H., Lafforgue, G. Mansfield, J. W., Rodriguez Egea, P., Bogre, L., and Grant, M. 2007. Pseudomonas syringae pv. tomato hijacks the Arabidopsis abscisic acid signalling pathway to cause disease. EMBO (Eur. Mol. Biol. Organ.) J. 26:1434-1443.

Edgar, R., Domrachev, M., and Lash, A. E. 2002. Gene Expression Omnibus: NCBI gene expression and hybridization array data repository. Nucleic Acids Res. 30:207-210.

Fowler, S. G., Cook, D., and Thomashow, M. F. 2005. Low temperature induction of Arabidopsis $C B F 1,2$, and 3 is gated by the circadian clock. Plant Physiol. 137:961-968.

Gilmour, S. J., Zarka, D. G., Stockinger, E. J., Salazar, M. P., Houghton, J. M., and Thomashow, M. F. 1998. Low temperature regulation of the 
Arabidopsis $C B F$ family of AP2 transcriptional activators as an early step in cold-induced COR gene expression. Plant J. 16:433-442.

Gilmour, S. J., Fowler, S. G., and Thomashow, M. F. 2004. Arabidopsis transcriptional activators $C B F 1, C B F 2$, and $C B F 3$ have matching functional activities. Plant Mol. Biol. 54:767-781.

Grant, S. R., Fisher, E. J., Chang, J. H., Mole, B. M., and Dangl, J. L. 2006. Subterfuge and manipulation: Type III effector proteins of phytopathogenic bacteria. Annu. Rev. Microbiol. 60:425-449.

Ha, S. B., and An, G. 1988. Identification of upstream regulatory elements involved in the developmental expression of the Arabidopsis thaliana $c a b 1$ gene. Proc. Natl. Acad. Sci. U.S.A. 85:8017-8021.

Hao, D., Yamasaki, K., Sarai, A., and Ohme-Takagi, M. 2002. Determinants in the sequence specific binding of two plant transcription factors, $C B F 1$ and NtERF2, to the DRE and GCC motifs. Biochemistry 41:4202-4208.

Harmer, S. L., Hogenesch, J. B., Straume, M., Chang, H. S., Han, B., Zhu, T., Wang, X., Kreps, J. A., and Kay, S. A. 2000. Orchestrated transcription of key pathways in Arabidopsis by the circadian clock. Science 290:2110-2113.

Hilson, P., Allemeersch, J., Altmann, T., Aubourg, S., Avon, A., Beynon, J., Bhalerao, R. P., Bitton, F., Caboche, M., Cannoot, B., Chardakov, V., Cognet-Holliger, C., Colot, V., Crowe, M., Darimont, C., Durinck, S., Eickhoff, H., de Longevialle, A. F., Farmer, E. E., Grant, M., Kuiper, M. T., Lehrach, H., Leon, C., Leyva, A., Lundeberg, J., Lurin, C., Moreau, Y., Nietfeld, W., Paz-Ares, J., Reymond, P., Rouze, P., Sandberg, G., Segura, M. D., Serizet, C., Tabrett, A., Taconnat, L., Thareau, V., Van Hummelen, P., Vercruysse, S., Vuylsteke, M., Weingartner, M., Weisbeek, P. J., Wirta, V., Wittink, F. R., Zabeau, M., and Small, I. 2004. Versatile gene-specific sequence tags for Arabidopsis functional genomics: Transcript profiling and reverse genetics applications. Genome Res. 14:2176-2189.

Jakoby, M., Weisshaar, B., Droge-Laser, W., Vicente-Carbajosa, J., Tiedemann, J., Kroj, T., and Parcy, F. 2002. bZIP transcription factors in Arabidopsis. Trends Plant Sci. 7:106-111.

Jones, J. D., and Dangl, J. L. 2006. The plant immune system. Nature 444:323-329.

Kay, S., Hahn, S., Marois, E., Hause, G., and Bonas, U. 2007. A bacterial effector acts as a plant transcription factor and induces a cell size regulator. Science 318:648-651.

Kimura, M., Yamamoto, Y. Y., Seki, M., Sakurai, T., Sato, M., Abe, T., Yoshida, S., Manabe, K., Shinozaki, K., and Matsui, M. 2003. Identification of Arabidopsis genes regulated by high light-stress using cDNA microarray. Photochem. Photobiol. 77:226-233.

Klusener, B., Young, J. J., Murata, Y., Allen, G. J., Mori, I. C., Hugouvieux, V., and Schroeder, J. I. 2002. Convergence of calcium signaling pathways of pathogenic elicitors and abscisic acid in Arabidopsis guard cells. Plant Physiol. 130:2152-2163.

Kolukisaoglu, U., Weinl, S., Blazevic, D., Batistic, O., and Kudla, J. 2004 Calcium sensors and their interacting protein kinases: Genomics of the Arabidopsis and rice CBL-CIPK signaling networks. Plant Physiol. 134:43-58.

Kushiro, T., Okamoto, M., Nakabayashi, K., Yamagishi, K., Kitamura, S., Asami, T., Hirai, N., Koshiba, T., Kamiya, Y., and Nambara, E. 2004. The Arabidopsis cytochrome P450 CYP707A encodes ABA 8'-hydroxylases: Key enzymes in ABA catabolism. EMBO (Eur. Mol. Biol. Organ.) J. 23:1647-1656.

Li, C., Bai, Y., Jacobsen, E., Visser, R., Lindhout, P., and Bonnema, G. 2006a. Tomato defense to the powdery mildew fungus: Differences in expression of genes in susceptible, monogenic- and polygenic resistance responses are mainly in timing. Plant Mol. Biol. 62:127-140.

Li, X., Duan, X., Jiang, H., Sun, Y., Tang, Y., Yuan, Z., Guo, J., Liang, W., Chen, L., Yin, J., Ma, H., Wang, J., and Zhang, D. 2006b. Genome-wide analysis of basic/helix-loop-helix transcription factor family in rice and Arabidopsis. Plant Physiol. 141:1167-1184.

Maleck, K., Levine, A., Eulgem, T., Morgan, A., Schmid, J., Lawton, K A., Dangl, J. L., and Dietrich, R. A. 2000. The transcriptome of Arabidopsis thaliana during systemic acquired resistance. Nat. Genet. 26:403-410

Marois, E., Van den Ackerveken, G., and Bonas, U. 2002. The Xanthomonas type III effector protein AvrBs3 modulates plant gene expression and induces cell hypertrophy in the susceptible host. Mol. Plant-Microbe Interact. 15:637-646.

Mauch-Mani, B., and Mauch, F. 2005. The role of abscisic acid in plantpathogen interactions. Curr. Opin. Plant Biol. 8:409-414.

Medina, J., Catala, R., and Salinas, J. 2001. Developmental and stress regulation of $R C I 2 A$ and $R C I 2 B$, two cold-inducible genes of Arabidopsis encoding highly conserved hydrophobic proteins. Plant Physiol. 125:1655-1666.

Medina, J., Rodriguez-Franco, M., Penalosa, A., Carrascosa, M. J., Neuhaus, G., and Salinas, J. 2005. Arabidopsis mutants deregulated in RCI2A expression reveal new signaling pathways in abiotic stress responses.
Plant J. 42:586-597.

Mitchell, H. J., Ayliffe, M. A., Rashid, K. Y., and Pryor, A. J. 2006. A rustinducible gene from flax (fis1) is involved in proline catabolism. Planta 223:213-222.

Mitsuya, S., Taniguchi, M., Miyake, H., and Takabe, T. 2005. Disruption of $R C I 2 A$ leads to over-accumulation of $\mathrm{Na}^{+}$and increased salt sensitivity in Arabidopsis thaliana plants. Planta 222:1001-1009.

Mohr, P. G., and Cahill, D. M. 2003. Abscisic acid influences the susceptibility of Arabidopsis thaliana to Pseudomonas syringae pv. tomato and Peronospora parasitica. Funct. Plant Biol. 30:461-469.

Nakano, T., Suzuki, K., Fujimura, T., and Shinshi, H. 2006. Genome-wide analysis of the ERF gene family in Arabidopsis and rice. Plant Physiol. 140:411-432.

Nurnberger, T., Brunner, F., Kemmerling, B., and Piater, L. 2004. Innate immunity in plants and animals: Striking similarities and obvious differences. Immunol. Rev. 198:249-266.

Nylander, M., Svensson, J., Palva, E. T., and Welin, B. V. 2001. Stressinduced accumulation and tissue-specific localization of dehydrins in Arabidopsis thaliana. Plant Mol. Biol. 45:263-279.

O'Connor, T. R., Dyreson, C., and Wyrick, J. J. 2005. Athena: A resource for rapid visualization and systematic analysis of Arabidopsis promoter sequences. Bioinformatics 21:4411-4413.

Okamoto, M., Kuwahara, A., Seo, M., Kushiro, T., Asami, T., Hirai, N. Kamiya, Y., Koshiba, T., and Nambara, E. 2006. CYP707A1 and CYP707A2, which encode abscisic acid 8'-hydroxylases, are indispensable for proper control of seed dormancy and germination in Arabidopsis. Plant Physiol. 141:97-107.

Pandey, G. K., Grant, J. J., Cheong, Y. H., Kim, B. G., Li, L., and Luan, S 2005. ABR1, an APETALA2-domain transcription factor that functions as a repressor of ABA response in Arabidopsis. Plant Physiol. 139:1185-1193.

Restrepo, S., Myers, K. L., del Pozo, O., Martin, G. B., Hart, A. L., Buell, C. R., Fry, W. R., and Smart, C. D. 2005. Gene profiling of a compatible interaction between Phytophthora infestans and Solanum tuberosum suggests a role for carbonic anhydrase. Mol. Plant-Microbe Interact. 18:913-922.

Reuber, T. L., Plotnikova, J. M., Dewdney, J., Rogers, E. E., Wood, W., and Ausubel, F. M. 1998. Correlation of defense gene induction defects with powdery mildew susceptibility in Arabidopsis enhanced disease susceptibility mutants. Plant J. 16:473-485.

Shinozaki, K., and Yamaguchi-Shinozaki, K. 2000. Molecular responses to dehydration and low temperature: Differences and cross-talk between two stress signaling pathways. Curr. Opin. Plant Biol. 3:217-223.

Stotz, H. U., Pittendrigh, B. R., Kroymann, J., Weniger, K., Fritsche, J., Bauke, A., and Mitchell-Olds, T. 2000. Induced plant defense responses against chewing insects. Ethylene signaling reduces resistance of Arabidopsis against Egyptian cotton worm but not diamondback moth. Plant Physiol. 124:1007-1018.

Tao, Y., Xie, Z., Chen, W., Glazebrook, J., Chang, H. S., Han, B., Zhu, T., Zou, G., and Katagiri, F. 2003. Quantitative nature of Arabidopsis responses during compatible and incompatible interactions with the bacterial pathogen Pseudomonas syringae. Plant Cell 15:317-330.

Toledo-Ortiz, G., Huq, E., and Quail, P. H. 2003. The Arabidopsis basic/ helix-loop-helix transcription factor family. Plant Cell 15:1749-1770.

Truman, W., de Zabala, M. T., and Grant, M. 2006. Type III effectors orchestrate a complex interplay between transcriptional networks to modify basal defense responses during pathogenesis and resistance. Plant $\mathrm{J}$. 46:14-33

Wilhelm, K. S., and Thomashow, M. F. 1993. Arabidopsis thaliana cor $15 b$, an apparent homologue of cor $15 a$, is strongly responsive to cold and ABA, but not drought. Plant Mol. Biol. 23:1073-1077.

Yamaguchi-Shinozaki, K., and Shinozaki, K. 2006. Transcriptional regulatory networks in cellular responses and tolerance to dehydration and cold stresses. Annu. Rev. Plant Biol. 57:781-803.

Zipfel, C., and Felix, G. 2005. Plants and animals: A different taste for microbes? Curr. Opin. Plant Biol. 8:353-360.

\section{AUTHOR-RECOMMENDED INTERNET RESOURCES}

The Institute for Genome Research database: www.tigr.org/tdb/e2k1/ath1 The Database of Arabidopsis Transcription Factors: datf.cbi.pku.edu.cn The Arabidopsis Information Resource (TAIR) GO annotations: www.arabidopsis.org/tools/bulk/go/index.jsp

AtGenExpress Visualization Tool: jsp.weigelworld.org/expviz/expviz.jsp Athena website: www.bioinformatics2.wsu.edu/cgi-bin/Athena/cgi/home.pl The CATMA website: www.catma.org

University of Utrecht Department of Biology Faculty website: genomics.bio.uu.nl

NCBI Gene Expression Omnibus database: www.ncbi.nlm.nih.gov/geo 